\title{
Bariatric Surgery-Associated Myelopathy
}

\author{
Sewar Asakly Ramit Magen-Rimon Ahmad Ighbariya Miriam Marjih-Shallufi \\ Tair Ben-Porat Sarit Ravid Ayelet Eran Vardit Gepstein Suhair Hanna \\ Ram Weiss
}

Department of Pediatrics, Ruth Children's Hospital, Rambam Medical Center, Haifa, Israel

\section{Keywords}

Bariatric surgery $\cdot$ Myelopathy $\cdot$ Nutritional deficiencies

\begin{abstract}
Bariatric surgery is gaining acceptance as an efficient treatment modality for adults and adolescents with morbid obesity. The early postbariatric period has the potential to induce an immunomodulatory imbalance due to the development or worsening of nutritional deficiencies, changes in hormonal balance (specifically after sleeve gastrectomy), and a shift in the proinflammatory cytokine profile along with a major change in the gut microbiome and permeability. These changes may induce encephalomyelitic T cell activity, change neural barrier permeability, and induce gut dysbioisis, favoring a proinflammatory metabolic profile. Such changes, in genetically prone individuals or those with additional risk factors, may lead to the development of myelopathy, particularly MS. Key Message: Postbariatric myelopathy is rare but should be considered in bariatric patients with relevant complaints in the postoperative period.

(C) 2021 The Author(s)

Published by S. Karger AG, Basel
\end{abstract}

Bariatric surgical procedures are gaining acceptance as an effective and sustainable treatment for patients suffering from morbid obesity and its related complications [1].
The most common procedures currently utilized include the Roux-en-Y gastric bypass (RYGB), sleeve gastrectomy (SG), and laparoscopic gastric banding (LAGB). Bariatric procedures induce weight loss by means of 2 basic mechanisms (which vary according to the procedure): mechanical restriction and malabsorption [2]. Additional systemic yet mechanistically important effects are driven by the hormonal and metabolic changes induced by such operations. Bariatric procedures lead to a substantial and relatively rapid weight loss during the first 12-24 months following surgery. In addition to weight loss, these procedures cause a significant reversal of obesitydriven comorbidities such as type 2 diabetes, hypertension, dyslipidemia, and obstructive sleep apnea [3]. Importantly, bariatric procedures initially lead to a consumption of a low-calorie diet inducing rapid weight loss and most patients are required to consume a lifetime replacement of multivitamins aiming at preventing significant nutritional deficiencies [4].

Myelopathies are defined as neurologic deficits related to the spinal cord [5]. Myelopathy can be the result of multiple etiologies, some that may manifest in the postoperative (early and late) phase of bariatric procedures. Specifically, metabolic myelopathies are caused by a spe-

S.A. and R.M.-R. contributed equally as first authors. karger@karger.com www.karger.com/ofa

Karger $\stackrel{\text { ' }}{5}$

BOPEN ACCESS
(C) 2021 The Author(s)

Published by S. Karger AG, Basel

This is an Open Access article licensed under the Creative Commons Attribution-NonCommercial-4.0 International License (CC BY-NC) (http://www.karger.com/Services/OpenAccessLicense), applicable to the online version of the article only. Usage and distribution for commercial purposes requires written permission.
Correspondence to:

Sewar Asakly, s_asakly@ rmc.gov.il 
Table 1. Results before and 3 months after the bariatric procedure

\begin{tabular}{|c|c|c|}
\hline Blood values & Preoperative & 3 months postoperative \\
\hline Hemoglobin, g/dL & 9.3 & 10.1 \\
\hline C-reactive protein, $\mathrm{mg} / \mathrm{dL}$ & & $0.69(<0.5)$ \\
\hline Creatine kinase, U/L & & $55(92-192)$ \\
\hline Albumin, $g / d L$ & 4.1 & 4.0 \\
\hline Iron, $\mu \mathrm{g} / \mathrm{dL}$ & 16 & $14(20-164)$ \\
\hline Ferritin, ng/mL & 10 & $8(10-120)$ \\
\hline Vitamin $B_{12}, \mathrm{pg} / \mathrm{mL}$ & 542 & 450 \\
\hline Coagulation factors & & normal \\
\hline Blood gases & & normal \\
\hline $25-\mathrm{OH}$ vitamin $\mathrm{D}_{3}, \mathrm{ng} / \mathrm{dL}$ & 20.2 & $16.4(20-50)$ \\
\hline Copper, $\mu \mathrm{g} / \mathrm{dl}$ & & $95(70-140)$ \\
\hline Vitamin $\mathrm{B}_{1}, \mathrm{nmol} / \mathrm{L}$ & & $68(>70)$ \\
\hline Complement & & normal \\
\hline Antinuclear antibodies $^{\mathrm{a}}$ & & negative \\
\hline Amino acids & & normal \\
\hline Immunoglobulins & & normal \\
\hline Anticardiolipin IgG and IgM & & negative \\
\hline Homocysteine & & normal \\
\hline Anti-MOG and anti-aquaporin- 4 antibodies & & negative \\
\hline CSF tests & Results & \\
\hline White blood cells & \multirow{7}{*}{\multicolumn{2}{|c|}{$\begin{array}{l}6 \text { lymphocytes } \\
\text { normal compared to the blood glucose } \\
\text { normal } \\
\text { Herpes simplex and Enterovirus were negative } \\
\text { negative } \\
\text { lymphocytes and monocytes } \\
\text { positive }\end{array}$}} \\
\hline Glucose & & \\
\hline Protein & & \\
\hline Viruses & & \\
\hline Culture & & \\
\hline Cytology & & \\
\hline Oligoclonal band & & \\
\hline
\end{tabular}

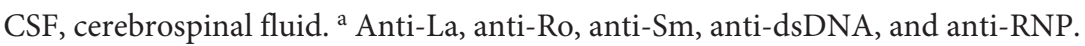

cific nutritional deficiency that is crucial for myelin and axon integrity and maintenance. As the postoperative period may be characterized by both nutritional deficiencies as well as a systemic (and specifically adipose tissue) stress response [6] induced by the catabolic weight loss phase, it is reasonable to assume that it may cause some newonset myelopathies to appear. Here, we describe a morbidly obese teenager who underwent SG and developed neurologic deficits 3 months after surgery. We further review potential mechanistic explanations for the development of postbariatric myelopathy.

\section{Case Description}

A 17-year-old female presented with progressive ascending lower extremity weakness, numbness, and paresthesia starting 4 days earlier. She described paresthesia below the nipple line and a progressive weakness of her lower limbs which meant she could walk independently but unsteadily. She had no history of fever or trauma. Following the onset of these symptoms, she reported urinary incontinence.

Past medical history included morbid obesity since early childhood, documented obstructive sleep apnea, and menorrhagia. The patient had undergone SG 3 months prior to admission. She had been advised to consume the standard postoperative diet, along with vitamin supplementation [7]. Following the operation, she lost $25 \mathrm{~kg}$ (i.e., an excess weight loss of 37\%). She did not take the vitamin supplements that were prescribed for her before or following the procedure. The patient had no vomiting but reported a very low caloric intake.

The patient was an only child. Both parents suffered from obesity and the mother had undergone bariatric surgery herself. The father passed away from an unknown medical condition. There was no history of any autoimmune disease in their parents or siblings.

Physical examination was unremarkable except for slight weakness in dorsiflexion (4/5) of the lower extremities. Deep tendon reflexes were +2 and symmetric with a negative Babinski sign bilaterally. Sensation was intact except for paresthesia below the nipple line. Gait was slightly unstable but did not fit to any specific 

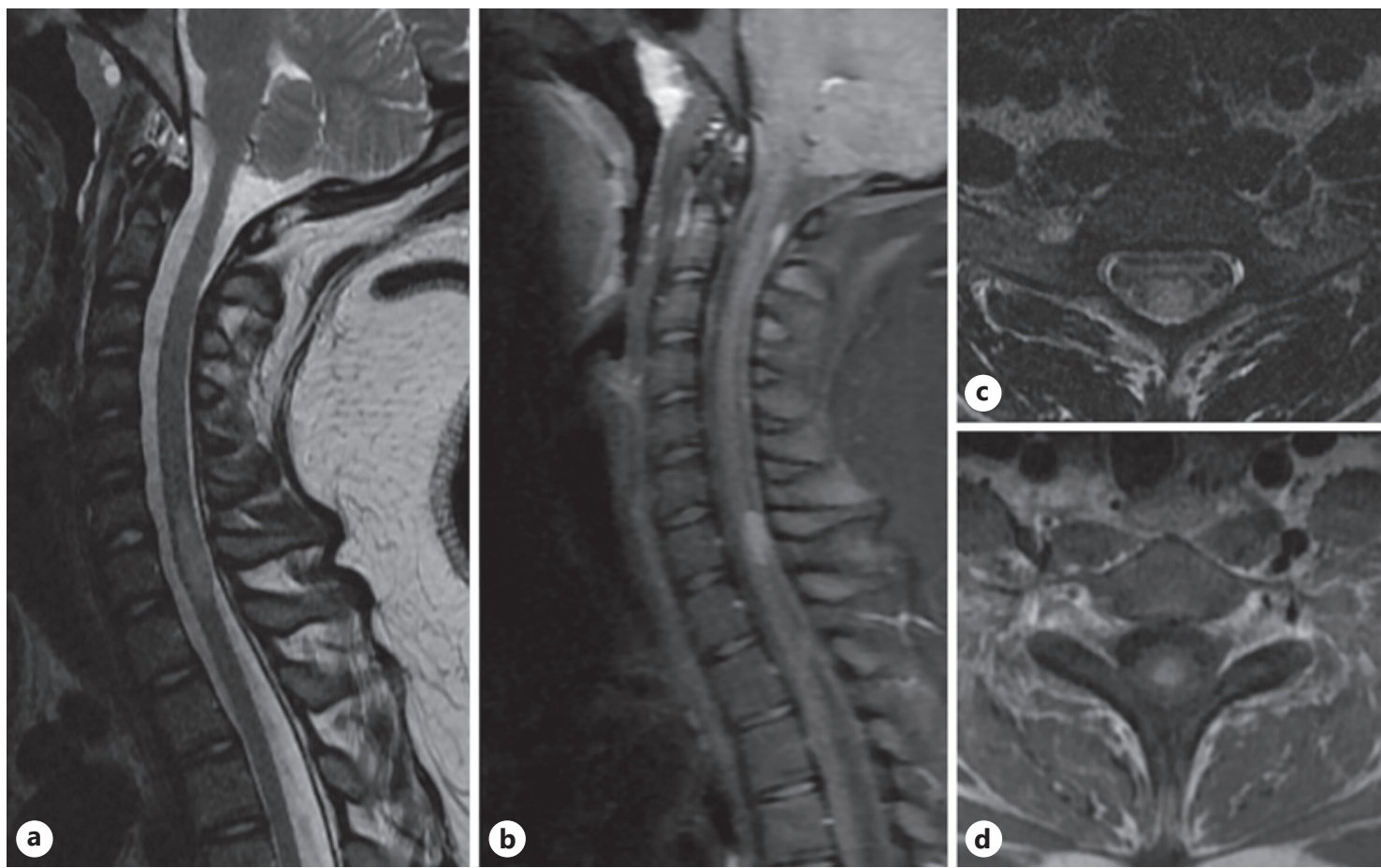

Fig. 1. a, c First spinal MRI examination showing longitudinal myelitis with increased T2 signal and slight cord expansion at $\mathrm{C} 6$ through vitamin $\mathrm{D}_{1}$ levels. $\mathbf{b}, \mathbf{d}$ Following gadolinium injection, there is central, almost complete enhancement, mainly involving the central cord.

neurological pattern. Normal rectal tone was noted and an electromyogram study was normal.

Following a normal cranial CT, a lumbar puncture revealed 6 lymphocytes along with normal glucose and protein levels. Cerebrospinal fluid (CSF) bacterial and viral assays were negative. CSF cytology revealed seemingly normal lymphocytes and monocytes.

The patient had a normal blood count and renal and liver function, and slightly elevated CRP (Table 1). Vitamin $\mathrm{B}_{12}$, vitamin E, and folic acid levels were normal, while low vitamin $\mathrm{B}_{1}$ was noted as well as a very low level of $25-\mathrm{OH}$ vitamin $\mathrm{D}_{3}$. Copper level was normal and toxicologic screening was negative. Anti-MOG and anti-aquaporin-4 antibodies were negative.

Due to the low blood levels of vitamin $\mathrm{B}_{1}$ and her clinical presentation of muscle weakness and suspected neuropathy, vitamin $B_{1}$ deficiency-related neuropathy was suspected. The patient was treated with an intravenous $\mathrm{B}_{1}$ supplement, vitamin $\mathrm{D}$, and an oral multivitamin supplement. This resulted in a minimal improvement of her clinical symptomatology. At this point, spinal and cranial MRI was performed. Spinal imaging demonstrated a longitudinally extensive myelitis manifesting as swelling of the spinal cord with high-signal intensity on T2-weighted images and strong enhancement between the lower C6 and T1 (Fig. 1). The lesion mainly involved the central gray matter. The brain MRI was normal.

A diagnosis of acute transverse myelitis was made, and steroid treatment was initiated. The patient was initially treated with highdose intravenous steroids and later with oral prednisone, followed by tapering of the dose. She experienced little improvement with this treatment regimen. As a result, she received a series of 6 plasmapheresis cycles that resulted in a significant improvement and was able to walk independently. Three weeks later, her symptoms deteriorated again, and she developed urinary incontinence. Repeated MRI revealed no major changes of the spinal lesion as well as a new lesion within the corpus callosum (not present 3 weeks earlier). A diagnosis of multiple sclerosis (MS) was made. Oligoclonal antibodies in the CSF later returned positive.

\section{Discussion}

We report a case of postbariatric surgery development of a myelopathy, later diagnosed as MS, in a female teenager. This is a rare occurrence and only a handful of cases have been previously described [8]. Neurological complications of bariatric surgery are uncommon and can result from surgical as well as nutritional complications. Most studies reported that only $1.3-16 \%$ of patients manifested with neurological complications during the follow-up [9], mainly peripheral neuropathies [10]. Regardless, the postoperative period of bariatric surgery represents a significant nutritional and catabolic stress that may lead to the development of serious myelopathies. We discuss the potential roles of nutritional, hormonal, and immunological effects of surgery in relation to the development of myelopathy. 


\section{Pathophysiology and Etiology of Myelopathies and of} MS

MS is a chronic inflammatory disease of the central nervous system (CNS) and is the most common cause of nontraumatic neurological disability in young adults [11]. The pathophysiology of MS development is not fully elucidated, but it appears to involve a combination of a genetic susceptibility along with nongenetic triggers such as infections and environmental exposures that, together, lead to an autoimmune dysregulation characterized by recurrent immune attacks on the CNS [12]. The disease appears to develop due to unregulated activation of cellmediated immune responses that target specific components of the CNS [13].

Acute transverse myelitis has an incidence of 1-4 new cases/1,000,000/year and occurs at all ages, with a typical bimodal peak in the second and fourth decades of life, with no difference between the genders, no seasonal variations, and no specific predisposing familial history [14]. Alongside infectious and inflammatory etiologies of this condition, nutritional deficiencies are a significant component of the differential diagnosis. Subacute combined degeneration has traditionally been used to describe the myeloneuropathy associated with vitamin $B_{12}$ deficiency. This myelopathy typically presents with physical findings suggestive of lesions within the dorsal column, corticospinal tract, or peripheral nerves. Copper deficiency can present with clinical and imaging findings similar to those of transverse myelitis. The most common manifestation of acquired copper deficiency is myelopathy or myeloneuropathy that resembles the subacute combined degeneration seen with vitamin $\mathrm{B}_{12}$ deficiency. Hematological manifestation of acquired copper deficiency includes anemia and neutropenia. Of the usual causes of acquired copper deficiency, the most common is a prior history of gastric surgery. Vitamin E deficiency has been shown to present with similar clinical findings, with a specific predilection to include the cerebellar pathways. Neurologic manifestations of vitamin E deficiency include peripheral neuropathies as well as a progressive spinocerebellar syndrome with corticospinal tract dysfunction.

Acute transverse myelitis can be the initial presentation of MS [15] (as in the case presented here), but MS typically presents with a partial myelitis, with either motor or sensory symptoms present, while bowel and bladder function is usually not compromised at this stage. The description of longitudinal extensive myelitis on presentation is more typical of the neuromyelitis optica spectrum. Our patient did not meet the diagnostic criteria for this condition.

\section{Postbariatric Nutritional Deficiencies}

Several reports have shown that morbidly obese individuals in general, and particularly bariatric surgery candidates, tend to have significant nutritional deficiencies [16]. These range from iron deficiency to clinically significant vitamin D depletion and low folic acid levels. Such observations have been observed in adults as well as in obese teenagers like our patient. It is well established that failure to replenish vitamin and mineral stores prior to the bariatric procedure usually results in substantial nutritional deficiencies following the operation [17]. Despite the fact that multivitamin supplementation is a critical component of the postoperative management of patients, low compliance along with objective difficulties of swallowing without vomiting, specifically in the early postoperative period, are common among these patients.

One of the suspected environmental factors is a higher latitude, as the prevalence and incidence of the disease is greater in northern areas such as in Scandinavia. Higher latitude correlates mainly with lower sunlight exposure, and it has been demonstrated that the risk of developing MS is inversely correlated with the amount of sunlight exposure [18]. The main metabolic impact of sunlight exposure in this context is on the synthesis of vitamin D. The specific role of vitamin D (but not sunlight UV exposure per se) in the pathophysiology of MS is supported by studies showing that a higher maternal dietary intake of the vitamin during pregnancy [19] and in young adults generally [20], seems to be protective against MS developing.

The mechanisms of involvement of vitamin D in MS development appear to be immunomodulatory. They involve effects on multiple subclasses of $\mathrm{T}$ and $\mathrm{B}$ lymphocytes. In vitro studies using 1-25 vitamin $\mathrm{D}$ show that it induces enhanced production of interleukin (IL)-10 by B lymphocytes [21], which is relevant in this context as there seems to be a link between B cell production of this IL and protection from autoimmune nervous system involvement [22, 23]. Similarly, in vitro vitamin $D$ induces an interference in plasma cell IgG secretion as well as an inhibition of development of post-switched memory B cells [24]. This may be relevant to the development and/or progression of MS, as high-affinity antibodies that may have switched class are postulated to be major drivers of both the development and progression of the disease. Indeed, our patient demonstrated significantly low levels of vitamin $\mathrm{D}$, which is commonly observed in obese bariatric surgery candidates [16] prior to and following surgery [25].

Vit $\mathrm{B}_{1}$ deficiency has been demonstrated in $5-30 \%$ of bariatric surgery candidates and in up to $30 \%$ within 5 years of bariatric procedures $[26,27]$. This vitamin is not synthe- 
sized endogenously in humans and maintenance of its normal levels depends on exogenous consumption. Low levels will typically present as peripheral neuropathy but can progress to full-blown Wernicke's encephalopathy. Our patient had low vitamin $B_{1}$ levels upon presentation, but she responded minimally to aggressive $B_{1}$ supplementation so her initial presentation with transverse myelitis was not due to this deficiency. The typical time frame for the clinical manifestations of vitamin $B_{1}$ deficiency to develop is up to 12 months, longer than that of our patient [28].

Vitamin $B_{12}$ deficiency common develops after SG due to the loss of a significant proportion of the stomach [17, 29]. Vitamin $B_{12}$ deficiency has been known for decades to be commonly present in patients with new-onset MS and is postulated to impact the development and clinical course of the disease. Whether vitamin $\mathrm{B}_{12}$ deficiency is indeed associated with MS and its exact potential causative role in disease development are still controversial in the literature [30]. Similarly, vitamin A deficiency is often encountered following SG [31]. An inverse association has been demonstrated between serum retinol levels and simultaneous and subsequent MRI outcomes, but not with clinical findings, in relapsing remitting MS [32]. Iron deficiency is very common after SG [25]. Iron supplementation is recommended postoperatively to all patients who undergo SG, but this may prove particularly tricky in the context of MS. Iron deposition in the brain has been suggested to contribute to the development of MS [33] but there is also a subgroup of patients with MS who improve significantly in response to iron supplementation [34]. These conflicting observations regarding the impact of iron on MS emphasize the broad spectrum of this disease and the necessity of an individualized nutritional approach. These observations suggest that vitamins, trace elements, and their metabolites may impact the clinical course and possibly the disease development in MS patients. Acquired myelopathy following bariatric procedures has been described due to copper deficiency. This complication tends to present years after the operation and is probably due to low copper consumption and absorption. As the absorption of copper takes place in the stomach and proximal duodenum [35], it is not surprising that copper deficiency may develop following bariatric procedures [36]. The time course of the development of this deficiency was less relevant for our patient who had a normal plasma copper concentration.

\section{Postbariatric Cytokine and Chemokine Dynamics}

Obesity is associated with a low-grade inflammatory chronic state, mainly due to cytokine secretion from var- ious lipid deposits [37]. This chronic subclinical inflammation is acutely exacerbated following bariatric procedures due to accelerated adipose tissue breakdown by lipolysis, typical of the rapid weight loss phase during the initial postoperative period [38]. The anatomical disruption of neuronal and hormonal pathways associated with bariatric procedures can lead to an activation of inflammatory signaling pathways and lead to accelerated cytokine production. For example, it been demonstrated that IL-8 concentrations tend to increase in the early postoperative phase of bariatric procedures. In patients with relapsing MS, IL-8 was found to be higher than in healthy controls. Interestingly, levels of IL- 8 tended to be much higher in the CSF than in the serum in such patients [39]. IL-6 levels have been shown to increase in the early postbariatric surgery period [40] and to remain so for at least 6 months, after which they decline. Studies in vivo and in vitro have found that IL- 6 is crucially involved in regulating the immune response in MS and may have a significant impact on the development and progression of the disease [41]. Specifically, overproduction of IL-6 has been shown to induce autoimmune diseases such as MS as well as rheumatoid arthritis (RA), in which $\mathrm{T}$ helper (Th) 17 cells are considered the primary drivers of pathology [42]. Th17 cells are one of the producers of IL-17, and high $I L$ 17 gene expression levels have been shown in mononuclear cells derived from the blood and CSF of MS patients [43] and the CD41 and CD81 T cells derived from MS lesions [44]. Th17 cells are able to cross and also damage the integrity of the blood-brain barrier (BBB), thus facilitating the infiltration of blood-derived proinflammatory cells into the nervous system. As such cells secrete IL-17A and many other cytokines, they may locally induce immune responses by altering the functionality multiple neuronal cells and networks, with the potential to cause axonal damage, demyelination, and neuronal apoptosis [45]. From the perspective of autoimmunity, there are several examples in the literature of other autoimmune conditions developing within less than a year of bariatric procedures, although the mechanisms involved are unclear [46]. Taken together, these observations may hint that the acute weight loss early in the postoperative period may, in some patients, create an immune imbalance that is involved in the development of autoimmune lesions of the nervous system.

\section{Postbariatric Hormonal Changes}

Weight loss, particularly bariatric procedures, has a profound impact on circulating concentrations of the multiple hormones involved in the metabolism. A spe- 
cific hormone relevant for this discussion is ghrelin. Ghrelin is produced by specialized endocrine cells of the stomach [47] and its concentration increases before meals to centrally stimulate food intake. Ghrelin concentration typically increases after diet-induced weight loss [48], but it is significantly reduced after bariatric procedures that excise substantial stomach mass, e.g., SG $[49,50]$. In the rodent model of MS (experimental autoimmune encephalomyelitis, EAE), ghrelin administration leads to a reduction of proinflammatory cytokines (e.g., IL-6 and TNF- $\alpha$ ) and also of cellular infiltrates in the spinal cord [51]. Ghrelin has been shown to reduce the presence and activation of Th1 and Th17 cells in the nervous system and to induce regulatory $\mathrm{T}$ cells in this model [52]. Ghrelin treatment in rodent models of traumatic brain injury has been shown to prevent cortical volume loss and neurodegeneration. In the same model, ghrelin improved posttraumatic motor deficits [53]. In other rodent models (diabetic rats), ghrelin has been shown to ameliorate astrocytic activation and reduce the expression of the abovementioned proinflammatory cytokines [54]. The mechanisms by which ghrelin induces its effects on the nervous system are still unclear, but the combination of the antiapoptotic and immune cell inflammatory modulatory effects may be advantageous in certain pathological conditions. Indeed, the anti-inflammatory role of ghrelin in the CNS is so profound that it has been proposed as a potential therapeutic intervention for MS [55].

A second hormone that is significantly reduced following dieting or surgically induced weight loss is leptin. Leptin is an adipocyte-derived hormone whose major role is to signal the size and availability of fat deposits (energy excess vs. shortage) to homeostatic brain centers and thus regulate energy expenditure [56]. Above and beyond its effects on energy regulation, leptin has been shown to impact immune function at several levels [57]. It has been hypothesized that a potential link exists between energy and nutritional metabolism and the pathogenesis of MS. Indeed, epidemiological data show that obesity, a high leptin state, increases the risk of developing MS in young females [58]. Indeed, elevated leptin levels are associated with chronic inflammatory conditions and autoimmune diseases (such as type 1 diabetes and lupus) in humans $[59,60]$. Supporting this hypothesis are the findings suggesting that proinflammatory mediators such as leptin maintain microenvironmental conditions that promote loss of immune self-tolerance. Leptin has also been shown to promote proinflammatory immune responses and inhibit the proliferation of anti- inflammatory regulatory T cells (T-regs) [61]. Moreover, leptin can affect the proliferation and the responsiveness of T-regs, a key subpopulation of $\mathrm{T}$ cells that are actively involved in the modulation of peripheral tolerance [62]. As mentioned above, orexigenic peptides and molecules such as neuropeptide $Y$ and ghrelin oppose the effects of leptin, in homeostatic hypothalamic nuclei in the context of caloric intake, and also on the peripheral immune response, and in diseases such as MS [63]. Studies on the natural history of MS have shown that $>60 \%$ of individuals exhibit reductions in body weight before MS onset, suggesting that the intrathecal balance between orexogenic factors (like ghrelin) and anorexogenic factors (like leptin) may be shifted in the early phases of the disease [61]. While bariatric procedures cause weight loss and thus reduce leptin levels, at least in the early phases postoperatively, patients still have higher than normal leptin levels. On the other hand, SG causes a drastic reduction in ghrelin and may thus shift the orexogenic/anorexogenic balance of the CNS to a relatively greater proinflammatory effect of leptin. Whether the acute reduction in ghrelin following SG plays a mechanistic role in the development of MS in predisposed individuals remains to be tested.

\section{Gut Microbiota and the Development of MS}

Several observations indicate that patients with MS display bacterial dysbiosis characterized by a reduced diversity and mass of the colonic microbiome [64]. Perturbations of the intestinal microbiome may play a role in the pathogenesis of inflammatory diseases such as MS. Specifically, using the EAE model, it has been shown that microbiota are prominent drivers of the triggering of autoimmune demyelination [65]. In addition, the gut microbiome may modulate the systemic and local host immune system, as well as modify the functionality and integrity of natural membranes and barriers. In the rodent model, dysbiosis induces the expression of complement $\mathrm{C} 3$ and the production of the anaphylatoxin $\mathrm{C} 3 \mathrm{a}$, while downregulating the expression of the Foxp 3 gene and anergy-related E3 ubiquitin ligase genes [66]. Thus, microbiome dysbiosis may be able to trigger the development of encephalitis-promoting $\mathrm{T}$ cells and induce the development of EAE.

Data from rodent models and from humans indicates that gut microbiota composition is modified following bariatric surgery, suggesting that weight reduction may have an impact on gut microbiota profiles [67]. Dietary content $[66,68]$ and weight loss per se [8] have been shown to alter the clinical course of EAE in rodents and 


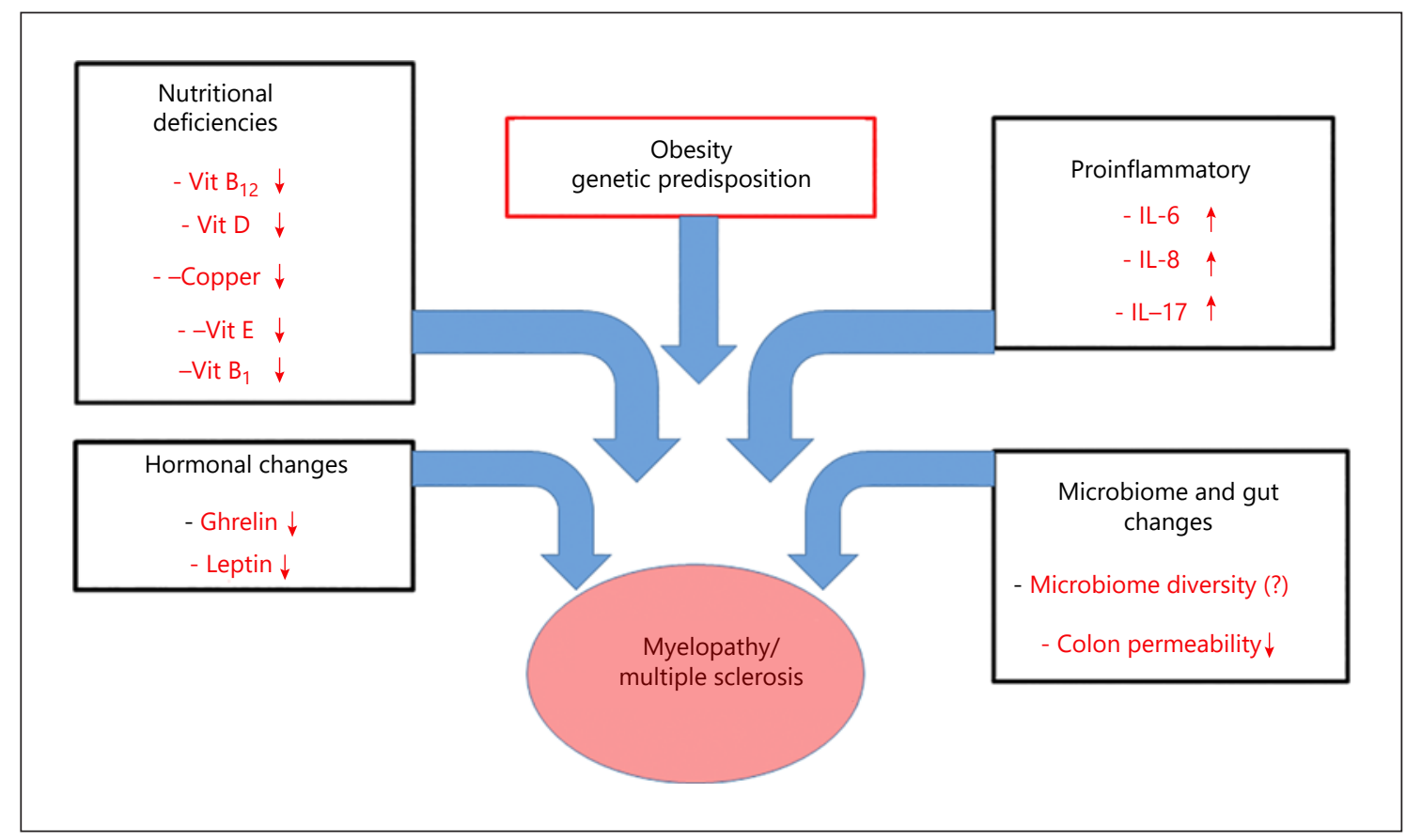

Fig. 2. The multiple elements related to bariatric surgery that may be involved in the development of myelopathies. Patients with a specific genetic predisposition who are obese are exposed to additional potential elements related to bariatric procedures that may induce the development of myelopathy and multiple sclerosis.

of MS in humans. Importantly, the RYGB procedure produces greater and more favorable changes in microbiota diversity and functional capacity than SG [69]. SG (the bariatric procedure that our patient underwent), on the other hand, induces an increase in the permeability of the colon, regardless of the small dynamic changes in microbiota [70]. While the changes of the microbiota profile induced by bariatric procedures and diet-induced weight loss have been viewed favorably in the context of weight dynamics (changing the microbiome to that more reminiscent of a lean individual), the modest change induced by SG and its impact on gut permeability may potentially have an adverse effect that alters immune tolerance and promotes an increase in specific $\mathrm{T}$ cell populations that can influence the development of MS, as observed in the EAE model.

An interesting point arises with regard to the impact of a very low-calorie diet (VLCD) in cases of established MS. There are several ongoing clinical trials testing fastmimicking and ketogenic diets in patients with MS [71]. These stem from observations regarding the positive effects of such diets in the rodent model of autoimmune encephalomyelitis [72]. It is postulated that the mechanism by which a dietary intervention may affect the clinical course of MS is related to the effects of the type and concentrations of specific nutrients that can influence the generation and functionality of lymphocytes, and thereby modulate autoimmunity and immunosenescence [73]. Similarly, caloric density and specific components of the diet may impact microbiota composition and thus alter the course of MS via the effects on relevant lymphocyte populations.

\section{Conclusion}

Bariatric surgery is gaining acceptance as an efficient treatment modality for adolescents with morbid obesity. The early postbariatric period has the potential to induce an immunomodulatory imbalance due to the development or worsening of nutritional deficiencies, changes in the hormonal balance (specifically following SG), and a shift in the proinflammatory cytokine profile, along with a major change in gut microbiome and permeability (Fig. 2). Such changes, in genetically prone individuals or those with additional risk factors, may lead to the development of a myelopathy, in general, and MS, in particular. These postbariatric complications are rare but should be considered in patients with relevant complaints in the postoperative period. 


\section{Statement of Ethics}

Written informed consent was obtained from the patient (now an adult) for publication of this case report and any accompanying MRI images.

\section{Conflict of Interest Statement}

There were no conflicts of interest. R.W. serves a consultant for Medtronic, Novo Nordisk, and Eli Lilly and received grants from the Israel Ministry of Science and Israel Ministry of Health (neither related to the topic in this paper). P.M.R. received a grant from the Israel Society of Pediatrics and the Israel Society of Pediatric Gastroenterology (neither related to the topic in this paper).

\section{Funding Sources}

There was no funding.

\section{Author Contributions}

S.A., R.M.-R., and R.W. wrote the manuscript and took part in clinical care. A.I., M.M.-S., T.B.-P., S.R., A.E., V.G., and S.H. commented on the text, added insights, and took part in the clinical care. All authors reviewed and approved the final version.

\section{References}

1 Wolfe BM, Kvach E, Eckel RH. Treatment of Obesity: Weight Loss and Bariatric Surgery. Circ Res. 2016 May;118(11):1844-55.

2 le Roux CW, Heneghan HM. Bariatric Surgery for Obesity. Med Clin North Am. 2018 Jan;102(1):165-82.

3 Puzziferri N, Roshek TB 3rd, Mayo HG, Gallagher R, Belle SH, Livingston EH. Long-term follow-up after bariatric surgery: a systematic review. JAMA. 2014 Sep;312(9):934-42.

4 Salameh BS, Khoukaz MT, Bell RL. Metabolic and nutritional changes after bariatric surgery. Expert Rev Gastroenterol Hepatol. 2010 Apr;4(2):217-23.

5 Hedera P. Hereditary and metabolic myelopathies. Handb Clin Neurol. 2016;136:769-85.

6 Kratz M, Hagman DK, Kuzma JN, FosterSchubert KE, Chan CP, Stewart S, et al. Improvements in glycemic control after gastric bypass occur despite persistent adipose tissue inflammation. Obesity (Silver Spring). 2016 Jul;24(7):1438-45.

7 Mechanick JI, Youdim A, Jones DB, Garvey WT, Hurley DL, McMahon MM, et al.; American Society for Metabolic \& Bariatric Surgery. Clinical practice guidelines for the perioperative nutritional, metabolic, and nonsurgical support of the bariatric surgery patient-2013 update: cosponsored by American Association of Clinical Endocrinologists, The Obesity Society, and American Society for Metabolic \& Bariatric Surgery. Obesity (Silver Spring). 2013 Mar;21 Suppl 1:S1-27.

8 Alanazy MH, Alomar MA, Aljafen BN, Muayqil TA. Multiple sclerosis and myasthenia gravis following severe weight loss. Neurosciences (Riyadh). 2018 Apr;23(2):158-61.

9 Koffman BM, Greenfield LJ, Ali II, Pirzada NA. Neurologic complications after surgery forobesity. MuscleNerve.2006Feb;33(2):16676.

10 Thaisetthawatkul P, Collazo-Clavell ML, Sarr MG, Norell JE, Dyck PJ. A controlled study of peripheral neuropathy after bariatric surgery. Neurology. 2004 Oct;63(8):1462-70.
11 Noseworthy JH, Lucchinetti C, Rodriguez M, Weinshenker BG. Multiple sclerosis. N Engl J Med. 2000 Sep;343(13):938-52.

12 Dendrou CA, Fugger L, Friese MA. Immunopathology of multiple sclerosis. Nat Rev Immunol. 2015 Sep;15(9):545-58.

13 Correale J, Gaitán MI, Ysrraelit MC, Fiol MP. Progressive multiple sclerosis: from pathogenic mechanisms to treatment. Brain. 2017 Mar;140(3):527-46.

14 Sá MJ. Acute transverse myelitis: a practical reappraisal. Autoimmun Rev. 2009 Dec;9(2):128-31.

15 Fisniku LK, Brex PA, Altmann DR, Miszkiel KA, Benton CE, Lanyon R, et al. Disability and T2 MRI lesions: a 20-year follow-up of patients with relapse onset of multiple sclerosis. Brain. 2008 Mar;131(Pt 3):808-17.

16 Ben-Porat T, Elazary R, Yuval JB, Wieder A, Khalaileh A, Weiss R. Nutritional deficiencies after sleeve gastrectomy: can they be predicted preoperatively? Surg Obes Relat Dis. 2015 Sep-Oct;11(5):1029-36.

17 Damms-Machado A, Friedrich A, Kramer KM, Stingel K, Meile T, Küper MA, et al. Preand postoperative nutritional deficiencies in obese patients undergoing laparoscopic sleeve gastrectomy. Obes Surg. 2012 Jun;22(6):881-9.

18 Lucas RM, Byrne SN, Correale J, Ilschner S, Hart PH. Ultraviolet radiation, vitamin D and multiple sclerosis. Neurodegener Dis Manag. 2015 Oct;5(5):413-24.

19 Mirzaei F, Michels KB, Munger K, O’Reilly E, Chitnis T, Forman MR, et al. Gestational vitamin $\mathrm{D}$ and the risk of multiple sclerosis in offspring. Ann Neurol. 2011 Jul;70(1):30-40.

20 Munger KL, Zhang SM, O’Reilly E, Hernán MA, Olek MJ, Willett WC, et al. Vitamin D intake and incidence of multiple sclerosis. Neurology. 2004 Jan;62(1):60-5.

21 Heine G, Niesner U, Chang HD, Steinmeyer A Zügel U, Zuberbier T, et al. 1,25-dihydroxyvitamin $\mathrm{D}$ (3) promotes IL-10 production in human B cells. Eur J Immunol. 2008 Aug;38(8):2210-8.
22 Duddy M, Niino M, Adatia F, Hebert S, Freedman M, Atkins $\mathrm{H}$, et al. Distinct effector cytokine profiles of memory and naive human B cell subsets and implication in multiple sclerosis. J Immunol. 2007 May;178(10):6092-9.

23 Duddy ME, Alter A, Bar-Or A. Distinct profiles of human $B$ cell effector cytokines: a role in immune regulation? J Immunol. 2004 Mar;172(6):3422-7.

24 Chen S, Sims GP, Chen XX, Gu YY, Chen S, Lipsky PE. Modulatory effects of 1,25-dihydroxyvitamin D3 on human B cell differentiation. J Immunol. 2007 Aug;179(3):1634-47.

25 Ben-Porat T, Elazary R, Goldenshluger A, Sherf Dagan S, Mintz Y, Weiss R. Nutritional deficiencies four years after laparoscopic sleeve gastrectomy-are supplements required for a lifetime? Surg Obes Relat Dis. 2017 Jul;13(7):1138-44.

26 van Rutte PW, Aarts EO, Smulders JF, Nienhuijs SW. Nutrient deficiencies before and after sleeve gastrectomy. Obes Surg. 2014 Oct;24(10):1639-46.

27 Saif T, Strain GW, Dakin G, Gagner M, Costa $\mathrm{R}$, Pomp A. Evaluation of nutrient status after laparoscopic sleeve gastrectomy 1, 3, and 5 years after surgery. Surg Obes Relat Dis. 2012 Sep-Oct;8(5):542-7.

28 Punchai S, Hanipah ZN, Meister KM, Schauer PR, Brethauer SA, Aminian A. Neurologic Manifestations of Vitamin B Deficiency after Bariatric Surgery. Obes Surg. 2017 Aug;27(8):2079-82.

29 Majumder S, Soriano J, Louie Cruz A, Dasanu CA. Vitamin B12 deficiency in patients undergoing bariatric surgery: preventive strategies and key recommendations. Surg Obes Relat Dis. 2013 Nov-Dec;9(6):1013-9.

30 Najafi MR, Shaygannajad V, Mirpourian M, Gholamrezaei A. Vitamin B(12) Deficiency and Multiple Sclerosis; Is there Any Association? Int J Prev Med. 2012 Apr;3(4):286-9.

31 Jalilvand A, Blaszczak A, Needleman B, Hsueh W, Noria S. Vitamin A Deficiency in Patients Undergoing Sleeve Gastrectomy and Gastric Bypass: A 2-Year, Single-Center Review. J Laparoendosc Adv Surg Tech A. 2020 Jan;30(1):20-30 
32 Løken-Amsrud KI, Myhr KM, Bakke SJ, Beiske AG, Bjerve KS, Bjørnarå BT, et al. Retinol levels are associated with magnetic resonance imaging outcomes in multiple sclerosis. Mult Scler. 2013 Apr;19(4):451-7.

33 Zamboni P. The big idea: iron-dependent inflammation in venous disease and proposed parallels in multiple sclerosis. J R Soc Med. 2006 Nov;99(11):589-93.

34 van Rensburg SJ, Kotze MJ, Hon D, Haug P, Kuyler J, Hendricks M, et al. Iron and the folate-vitamin B12-methylation pathway in multiple sclerosis. Metab Brain Dis. 2006 Sep;21(2-3):121-37.

35 Myint ZW, Oo TH, Thein KZ, Tun AM, Saeed H. Copper deficiency anemia: review article. Ann Hematol. 2018 Sep;97(9):1527-34.

36 Griffith DP, Liff DA, Ziegler TR, Esper GJ, Winton EF. Acquired copper deficiency: a potentially serious and preventable complication following gastric bypass surgery. Obesity (Silver Spring). 2009 Apr;17(4):827-31.

37 Wensveen FM, Valentić S, Šstan M, Turk Wensveen T, Polić B. The "Big Bang" in obese fat: events initiating obesity-induced adipose tissue inflammation. Eur J Immunol. 2015 Sep;45(9):2446-56.

38 Federico A, D’Aiuto E, Borriello F, Barra G, Gravina AG, Romano M, et al. Fat: a matter of disturbance for the immune system. World J Gastroenterol. 2010 Oct;16(38):4762-72.

39 Sisay S, Lopez-Lozano L, Mickunas M, Quiroga-Fernández A, Palace J, Warnes G, et al. Untreated relapsing remitting multiple sclerosis patients show antibody production against latent Epstein Barr Virus (EBV) antigens mainly in the periphery and innate immune IL-8 responses preferentially in the CNS. J Neuroimmunol. 2017 May;306:40-5.

40 Lindegaard $\mathrm{KK}$, Jorgensen $\mathrm{NB}$, Just $\mathrm{R}$, Heegaard PM, Madsbad S. Effects of Rouxen-Y gastric bypass on fasting and postprandial inflammation-related parameters in obese subjects with normal glucose tolerance and in obese subjects with type 2 diabetes. Diabetol Metab Syndr. 2015 Feb;7(1):12.

41 Janssens K, Slaets H, Hellings N. Immunomodulatory properties of the IL- 6 cytokine family in multiple sclerosis. Ann N Y Acad Sci. 2015 Sep;1351(1):52-60.

42 Kimura A, Kishimoto T. IL-6: regulator of Treg/Th17 balance. Eur J Immunol. 2010 Jul;40(7):1830-5.

43 Matusevicius D, Kivisäkk P, He B, Kostulas N, Ozenci V, Fredrikson S, et al. Interleukin-17 mRNA expression in blood and CSF mononuclear cells is augmented in multiple sclerosis. Mult Scler. 1999 Apr;5(2):101-4.

44 Tzartos JS, Friese MA, Craner MJ, Palace J, Newcombe J, Esiri MM, et al. Interleukin-17 production in central nervous system-infiltrating T cells and glial cells is associated with active disease in multiple sclerosis. Am J Pathol. 2008 Jan;172(1):146-55.

45 Wang X, Ma C, Wu J, Zhu J. Roles of T helper 17 cells and interleukin-17 in neuroautoimmune diseases with emphasis on multiple sclerosis and Guillain-Barré syndrome as well as their animal models. J Neurosci Res. 2013 Jul;91(7):871-81.

46 Cañas CA, Echeverri AF, Ospina FE, Suso JP, Agualimpia A, Echeverri A, et al. Is Bariatric Surgery a Trigger Factor for Systemic Autoimmune Diseases? J Clin Rheumatol. 2016 Mar;22(2):89-91.

47 Kojima M, Hosoda H, Date Y, Nakazato M, Matsuo H, Kangawa K. Ghrelin is a growth-hormone-releasing acylated peptide from stomach. Nature. 1999 Dec;402(6762):656-60.

48 Zigman JM, Bouret SG, Andrews ZB. Obesity Impairs the Action of the Neuroendocrine Ghrelin System. Trends Endocrinol Metab. 2016 Jan;27(1):54-63.

49 Kalinowski P, Paluszkiewicz R, Wróblewski T, Remiszewski P, Grodzicki M, Bartoszewicz Z, et al. Ghrelin, leptin, and glycemic control after sleeve gastrectomy versus Roux-en-Y gastric bypass-results of a randomized clinical trial. Surg Obes Relat Dis. 2017 Feb;13(2):181-8.

50 Anderson B, Switzer NJ, Almamar A, Shi X, Birch DW, Karmali S. The impact of laparoscopic sleeve gastrectomy on plasma ghrelin levels: a systematic review. Obes Surg. 2013 Sep;23(9):1476-80.

51 Theil MM, Miyake S, Mizuno M, Tomi C, Croxford JL, Hosoda H, et al. Suppression of experimental autoimmune encephalomyelitis byghrelin. J Immunol.2009 Aug;183(4):285966.

52 Souza-Moreira L, Delgado-Maroto V, Morell M, O'Valle F, Del Moral RG, Gonzalez-Rey E. Therapeutic effect of ghrelin in experimental autoimmune encephalomyelitis by inhibiting antigen-specific Th1/Th17 responses and inducing regulatory $\mathrm{T}$ cells. Brain Behav Immun. 2013 May;30:54-60.

53 Lopez NE, Lindsay G, Karina LR, Mary HA, Putnam J, Eliceiri B, et al. Ghrelin decreases motor deficits after traumatic brain injury. J Surg Res. 2014 Mar;187(1):230-6.

54 Zhao Y, Shen Z, Zhang D, Luo H, Chen J, Sun $\mathrm{Y}$, et al. Ghrelin ameliorates nerve growth factor Dysmetabolism and inflammation in STZ-induced diabetic rats. Metab Brain Dis. 2017 Jun;32(3):903-12.

55 de Candia P, Matarese G. Leptin and ghrelin: Sewing metabolism onto neurodegeneration. Neuropharmacology. 2018;136(Pt B):307-16.

56 Ahima RS, Flier JS. Adipose tissue as an endocrine organ. Trends Endocrinol Metab. 2000 Oct;11(8):327-32.

57 La Cava A, Matarese G. The weight of leptin in immunity. Nat Rev Immunol. 2004 May;4(5):371-9.

58 Munger KL, Chitnis T, Ascherio A. Body size and risk of MS in two cohorts of US women. Neurology. 2009 Nov;73(19):1543-50.

59 Härle P, Pongratz G, Weidler C, Büttner R, Schölmerich J, Straub RH. Possible role of leptin in hypoandrogenicity in patients with systemic lupus erythematosus and rheumatoid arthritis. Ann Rheum Dis. 2004 Jul;63(7):809-16.

60 Iacobellis G, Diaz S, Mendez A, Goldberg R. Increased epicardial fat and plasma leptin in type 1 diabetes independently of obesity. Nutr Metab Cardiovasc Dis. 2014 Jul;24(7):725-9.

61 Matarese G, Carrieri PB, Montella S, De Rosa V, La Cava A. Leptin as a metabolic link to multiple sclerosis. Nat Rev Neurol. 2010 Aug;6(8):455-61.

62 Taleb S, Herbin O, Ait-Oufella H, Verreth W, Gourdy P, Barateau V, et al. Defective leptin/ leptin receptor signaling improves regulatory $\mathrm{T}$ cell immune response and protects mice from atherosclerosis. Arterioscler Thromb Vasc Biol. 2007 Dec;27(12):2691-8.

63 Bedoui S, Miyake S, Lin Y, Miyamoto K, Oki S, Kawamura N, et al. Neuropeptide Y (NPY) suppresses experimental autoimmune encephalomyelitis: NPY1 receptor-specific inhibition of autoreactive Th1 responses in vivo. J Immunol. 2003 Oct;171(7):3451-8.

64 Swidsinski A, Dörffel Y, Loening-Baucke V, Gille C, Göktas Ö, Reißhauer A, et al. Reduced Mass and Diversity of the Colonic Microbiome in Patients with Multiple Sclerosis and Their Improvement with Ketogenic Diet. Front Microbiol. 2017 Jun;8:1141.

65 Calvo-Barreiro L, Eixarch H, Montalban X, Espejo C. Combined therapies to treat complex diseases: the role of the gut microbiota in multiple sclerosis. Autoimmun Rev. 2018 Feb;17(2):165-74.

66 Yadav SK, Boppana S, Ito N, Mindur JE, Mathay MT, Patel A, et al. Gut dysbiosis breaks immunological tolerance toward the central nervous system during young adulthood. Proc Natl Acad Sci USA. 2017 Oct;114(44):E9318-27.

67 Aron-Wisnewsky J, Doré J, Clement K. The importance of the gut microbiota after bariatric surgery. Nat Rev Gastroenterol Hepatol. 2012 Oct;9(10):590-8.

68 He B, Hoang TK, Tian X, Taylor CM, Blanchard E, Luo M, et al. Lactobacillus reuteri Reduces the Severity of Experimental Autoimmune Encephalomyelitis in Mice by Modulating Gut Microbiota. Front Immunol. 2019 Mar;10:385.

69 Murphy R, Tsai P, Jüllig M, Liu A, Plank L, Booth M. Differential Changes in Gut Microbiota After Gastric Bypass and Sleeve Gastrectomy Bariatric Surgery Vary According to Diabetes Remission. Obes Surg. 2017 Apr;27(4):917-25.

70 Kellerer T, Brandl B, Büttner J, Lagkouvardos I, Hauner H, Skurk T. Impact of Laparoscopic Sleeve Gastrectomy on Gut Permeability in Morbidly Obese Subjects. Obes Surg. 2019 Jul;29(7):2132-43.

71 Brenton JN, Banwell B, Bergqvist AG, LehnerGulotta D, Gampper L, Leytham E, et al. Pilot study of a ketogenic diet in relapsing-remitting MS. Neurol Neuroimmunol Neuroinflamm. 2019 Apr;6(4):e565.

72 Choi IY, Piccio L, Childress P, Bollman B, Ghosh A, Brandhorst S, et al. A Diet Mimicking Fasting Promotes Regeneration and Reduces Autoimmunity and Multiple Sclerosis Symptoms. Cell Rep. 2016 Jun;15(10):2136-46.

73 Choi IY, Lee C, Longo VD. Nutrition and fasting mimicking diets in the prevention and treatment of autoimmune diseases and immunosenescence. Mol Cell Endocrinol. 2017 Nov;455:4-12. 